\title{
Computer-Mediated Assessment of Higher-Order Thinking Development
}

\author{
Oleg Tilchin ${ }^{1} \&$ Jamal Raiyn ${ }^{1}$ \\ ${ }^{1}$ Computer Science Department Al-Qasemi Academic College of Education, Baqa El-Gharbieh, Israel \\ Correspondence: Oleg Tilchin, Academic College of Education P.O. Box 124, Baqa El-Gharbieh 30100, Israel. E-mail: \\ oletilchin@gmail.com
}

Received: January 8, 2015

Accepted: February 1, 2015

Online Published: February 3, 2015

doi:10.5430/ijhe.v4n1p225

URL: http://dx.doi.org/10.5430/ijhe.v4n1p225

\begin{abstract}
Solving complicated problems in a contemporary knowledge-based society requires higher-order thinking (HOT). The most productive way to encourage development of HOT in students is through use of the Problem-based Learning (PBL) model. This model organizes learning by solving corresponding problems relative to study courses. Students are directed to develop HOT skills needed for problem-solving that are essential for their future professional activities. However, in order to promote effective HOT skills development of students in PBL learning environment, enhancement of the model is required. The model enhancement can be attained through specific computer-mediated assessment of learning of students. In this paper we introduce an innovative approach to complex, adaptive, and computer-mediated assessment of HOT skills development of individual students. The complexity of assessment is expressed by forming the combined assessments of HOT skills of different types. Adaptation of assessment to the process of HOT skills development is expressed by changes in an instructor's fixed assessments by crossing from one phase of PBL to another. Assessment adaptation is provided for individual students as for a study group. Computer-mediation of assessment is provided by a Computer Assessment Tool which promotes students' HOT skills development and facilitates the assessment process for an instructor. The proposed coefficient of success of HOT skills development serves as an effective tool of analysis of this process.
\end{abstract}

Keywords: Problem-Based Learning, Higher-Order thinking, Complex adaptive assessment, Computer-Mediated Assessment

\section{Introduction}

Solving complicated problems in a contemporary knowledge-based society requires higher-order thinking (HOT), which is provided as a result of developing mental skills in students. The most suitable model aimed at effective HOT skills development is the Problem-based Learning (PBL) model (Duch, Groh, Allen, 2001; Amador, Miles, Peters, 2006; Barell, 2006; Barret \& Moore, 2010). According to this model, self-directed learning intends: problem determination; generation of a set of possible ideas for problem solving and a choice of a constructive idea; gaining needed information for problem solving, and problem solving actions. However, there are obstacles that make implementation of the PBL model difficult (Boud \& Feletti, 1997; Schwartz, Mennin, and Webl, 2001). The main obstacles are that students are not fully prepared for learning on their own; they are not encouraged enough to develop HOT skills; and it is an extra-heavy workload for an instructor.

The obstacles can be overcome through creation of a PBL environment which is favorable for HOT skills development. According to conducted research (Hannafin \& Land, 1997; Jonassen, 1998; Bransford, Brown, and Cocking, 1999; Baden \& Major, 2004; Pettigrew \& Scholter, 2010), such an environment should be:

- HOT skills-centered (an instructor must focus on HOT skills development for students);

- Student-centered (an instructor should encourage student interest in problem solving and critical thinking);

- Student adaptive (adaptation to the given student though testing or monitoring his (her) performance);

- Assessment centered (an instructor should provide high quantity and quality of assessments while stimulating students for HOT skills development);

- Computer-supported (using computer tools to decrease an extra-heavy workload for an instructor).

The central role in the creation of a PBL environment favorable for HOT is given to an instructor. The instructor should guide, foster, facilitate, and stimulate HOT skills development. A specific approach to computer-mediated assessment of HOT skills development in students can promote realization of this role of an instructor. 
The approach should be based on the following assessment principles (Macdonald \& Savin-Baden, 2004; Brookhart, 2010): specify clearly and exactly the matter of assessment; assessment is an instruction tool and not an evaluation mechanism; an assessment should keep learners motivated and involved; flexibility and complexity of assessment should be provided; assessment should be relevant to desired learning outcomes, and assessment should be a guided, adaptive, formative, and summative process.

The proposed systematic approach is aimed at computer-mediated complex adaptive assessment of HOT skills development of individual students and a class. The systematic approach should be ensured through reliability, validity, and usability of assessment.

\section{Related Research}

The goal of the proposed approach is enhancing a PBL model through computer-mediated assessment of HOT skills development in students. Organized correctly, the assessment process drives developing HOT skills needed for problem solving. The approaches, methods, and tools reviewed here are examined relative to various aspects of this process.

Knight (2000) pointed to the need of a systematic approach to the assessment of students' learning which provides reliability, validity, and usability. Moallem (2007) considers the process of evaluation relative to the following stages: initial assessment, progress assessment, and product assessment. Ma and Zhou (2000) suggested a fuzzy set approach to assess outcomes of student learning. These authors claim that their aim is encouraging students to participate in the whole learning process. Tillema (2010) is quite right contending that the function of formative assessment is to promote learning. Papanastasiou (2014) defined adaptive assessment as a type of assessment that is set for each student taking into account an assessment of his (her) previous performance. This allows an assessment to be more accurate of individual ability.

Savery (2006) affirms that the goals of PBL are knowledge building and adoption of a problem-solving process. Hence, student progress towards the goals of PBL should be assessed. Lovie-Kitchin (2001) rightly claims assessment methods should be congruent with the PBL process. Macdonald and Savin-Baden (2004) stressed the need for specific assessment methods for PBL. The authors note assessment should reflect the practical orientation of PBL. Consequently, HOT skills should be assessed. Brookhart (2010) asserts that holding students accountable for HOT through assessment increases student motivation and improves the results of learning. Student assessment is realized through reflection on built knowledge.

Alam (2014) emphasized the importance of using technology in teaching and learning. The author demonstrated that the use of computer-based assessments can improve traditional methods of assessment and learning outcomes. Ma (2002) developed a decision support system for assessing PBL. Assessment criteria and their weights are based on the use of mathematical decision methods.

The analysis of publications above shows that no a straightforward systematic approach exists to enhancing the PBL model due to computer mediated complex adaptive assessment of HOT skills development. The proposed systematic approach will promote productive HOT skills development due to the:

- Reliability, validity, and usability of assessment

- Stimulation of HOT skills development in students through complex and adaptive assessment

- Flexibility, responsiveness, and versatility of assessment caused by computer mediation

- Capacity of changing a set of HOT skills for assessment

- Facilitation of instructor work

- Management of HOT skills development

\section{The Systematic Approach to Computer-Mediated Assessment of HOT Development}

The aim of the proposed systematic approach is realizing complex, adaptive, and computer mediated assessment of developing HOT skills needed for problem solving. Complexity of assessment is provided by forming the combined assessments of HOT skills of different types. Adaptation of assessment to the process of HOT skills development is expressed by changes in fixed instructor assessments by crossing from one phase of PBL to another. Computer mediation facilitates the assessment process for an instructor.

There are two distinct types of HOT skills: analytical and creative thinking skills. Analytical or logical thinking realizes critical thinking and help select the best alternative. The analytical thinking skills are: ordering, comparing, contrasting, evaluating, and selecting. Creative thinking skills are needed for problem solving. The creative thinking 
skills are efficiency (producing many ideas), flexibility (producing a broad range of ideas), originality (producing uncommon ideas), and elaboration (developing ideas) (Bednarz, 2011; Cottrell, 2011; Cottrell, 2013).

The systematic approach ensures reliability, validity, and usability of assessment. Reliability of student assessment is attained through assessing each skill and their aggregates. Validity of assessment is provided by the change of fixed assessment of skills on the basis of learning progress. Usability is caused by the simplicity and transparency of the assessment process. The approach intends developing a method of complex adaptive assessment of HOT skills, and a Computer Assessment Tool (CAT) promoting HOT skills development of students and facilitating the assessment process for an instructor.

\subsection{The method of complex dynamic assessment of HOT skills}

The proposed method consists of: setting fixed initial assessments of HOT skills of different types for the first study phase of a course based on the PBL model; assessment of the individual skills; realizing combined assessments for each type of HOT skills; and forming adaptive assessments for the following study phases of a course on the basis of analysis of determined coefficients of success of HOT skills development. Consequently, the method is realized through a sequence of the steps:

1. Setting fixed initial assessments of HOT skills

2. Assessing development of analytical thinking skills

3. Assessing development of creative thinking skills

4. Forming combined formative assessments of HOT skills development

5. Determining a coefficient of success of HOT skills development

6. Developing Adaptive Assessments

A. Setting fixed initial assessments of HOT skills

The fixed initial assessments are set for each HOT skill as for each type of skill set. Difference of the fixed initial assessments of the skills expresses the preference of an instructor in the development of certain skills during the first study stage of a course based on PBL. An example of setting the fixed initial assessments is represented by Table1. The maximum fixed initial assessments are set for the "Contrasting" skill from the "Analytical" type and the "Originality" skill from the "Creative" type. Hence, these skills have the greatest need for development.

Table 1. Fixed initial assessments of HOT skills

\begin{tabular}{ccc}
\hline The type of thinking skills & Skills name & $\begin{array}{c}\text { The fixed initial } \\
\text { assessments (\%) }\end{array}$ \\
\hline \multirow{3}{*}{ Analytical (40\%) } & ordering & 8 \\
& comparing & 6 \\
& contrasting & 14 \\
& evaluating & 7 \\
& selecting & 5 \\
& efficiency & 16 \\
& flexibility & 12 \\
Creative (60\%) & originality & 22 \\
& elaboration & 10 \\
\hline
\end{tabular}

B. Assessing development of analytical thinking skills

An instructor prepares a complete list of questions which concern a study course by a student group. The questions of the list should examine analytical thinking skills after the first study stage of a course based on PBL. Next, the instructor composes individual lists of control questions on the basis of the complete list. An individual list can contain some questions for examination of a certain skill. The control questions from an individual list should provide examination of all analytical skills.

A student's skill development is assessed by an instructor through the answers given by a student to control questions from the individual list. An instructor assessment of a student answer to a question varies from zero to the fixed initial assessment of analytical skill corresponding to a question. If a student cannot answer a question, or an answer is incorrect, then an instructor assessment is equal to zero. If a student answers a question corresponding to certain skill correctly, an instructor assessment is equal to fixed initial assessment of corresponding analytical skill. It means he or 
she has developed this skill. If a student answer is not full, an instructor sets suitable assessment. As a result, an assessment of a student is made. Assessments of other students from a study group are set analogously. The obtained assessments allow an instructor to assess lack of developing students' analytical skills through comparison of the results of student answers with fixed initial assessments. An example of assessment of developing analytical skills in students is represented by Table2. Formative assessments of analytical skills development in student $\mathrm{s}_{1}, \mathrm{~s}_{2}$, and $\mathrm{s}_{3}$ are 11, 21 , and 35 , accordingly.

Table 2. Formative assessments of analytical skills development in students

\begin{tabular}{ccccc}
\hline The Questions & $\begin{array}{c}\text { The fixed initial } \\
\text { assessments of } \\
\text { analytical skills }\end{array}$ & $\begin{array}{c}\text { Student } \mathrm{S}_{1} \\
\text { assessment }\end{array}$ & $\begin{array}{c}\text { Student } \mathrm{S}_{2} \\
\text { assessment }\end{array}$ & $\begin{array}{c}\text { Student } \mathrm{S}_{3} \\
\text { assessment }\end{array}$ \\
\hline $\mathbf{q}_{\mathbf{1 1}}$ & Ordering 4\% & 0 & 4 & 3 \\
$\mathbf{q}_{\mathbf{1 2}}$ & $\begin{array}{c}\text { Ordering 4\% } \\
\text { Comparing 6\% }\end{array}$ & 0 & 4 & 3 \\
$\mathbf{q}_{\mathbf{2 1}}$ & Contrasting 7\% & 0 & 3 & 5 \\
$\mathbf{q}_{\mathbf{3 1}}$ & Contrasting 7\% & 0 & 7 & 7 \\
$\mathbf{q}_{\mathbf{3 2}}$ & Evaluating 7\% & 3 & 3 & 7 \\
$\mathbf{q}_{\mathbf{4 1}}$ & Selecting 5\% & 5 & 0 & 6 \\
$\mathbf{q}_{\mathbf{5 1}}$ & & & \\
\hline
\end{tabular}

C. Assessing development of creative thinking skills

An instructor prepares a complete list of control problems for solving by study group students. The problems from the list should examine creative thinking skills. Next, the instructor composes individual lists of control problems based on the complete list. The aggregate of the control problems of an individual list should examine development of all creative skills. Development of student skills is assessed by an instructor during problem solving from the individual list.

An instructor assessment of a student creative skill varies from zero to the fixed initial assessments of a creative skill. If a student didn't reveal presence of a certain creative skill owing to solving individual control problems, an instructor assessment is equal to zero. It means the student did not develop this skill. If a student solved an individual control problem partially, an instructor sets suitable assessment. If a student revealed the presence of a certain creative skill owing to solving individual control problems, an instructor assessment is equal to the fixed initial assessments of the skill. It means the student developed this skill. As a result, a formative assessment of creative thinking skills in a student is made. Formative assessments of developing creative skills in other students in a study group are determined analogously. An example of assessment of developing creative skills in students is represented by Table 3 . Formative assessments of the creative skills development in student $\mathrm{s}_{1}, \mathrm{~s}_{2}$, and $\mathrm{s}_{3}$ are 16,22 , and 48 , accordingly. The obtained formative assessments allow for assessing lack of students' creative skills development through comparison of the results of an individual student's solving of control problems with fixed initial assessments.

Table 3. Formative assessments of creative skills development in students

\begin{tabular}{cccc}
\hline $\begin{array}{c}\text { The fixed initial } \\
\text { assessments of creative } \\
\text { skills }\end{array}$ & $\begin{array}{c}\text { Student } \mathrm{S}_{1} \\
\text { assessment }\end{array}$ & $\begin{array}{c}\text { Student } \mathrm{S}_{2} \\
\text { assessment }\end{array}$ & $\begin{array}{c}\text { Student } \mathrm{S}_{3} \\
\text { assessment }\end{array}$ \\
\hline $\begin{array}{c}\text { Efficiency 16\% } \\
\text { Flexibility 12\% }\end{array}$ & 6 & 4 & 16 \\
Originality 22\% & 0 & 12 & 12 \\
Elaboration 10\% & 10 & 0 & 20 \\
\hline
\end{tabular}

D. Forming combined formative assessments of HOT skills development

Combined assessments of developing HOT skills are determined as a result of summation of corresponding assessments of analytical and creative skills. An example of the combined assessments based on data from Table 2 and Table 3 are presented in Table 4. 
Table 4. Combined formative assessments of the HOT skills development

\begin{tabular}{llll}
\hline & $\mathrm{S}_{1}$ & $\mathrm{~S}_{2}$ & $\mathrm{~S}_{3}$ \\
\hline $\begin{array}{l}\text { Formative assessments of developing } \\
\text { analytical skills }\end{array}$ & 11 & 21 & 35 \\
$\begin{array}{l}\text { Formative assessments of developing } \\
\text { creative skills }\end{array}$ & 16 & 22 & 48 \\
$\begin{array}{l}\text { Combined formative assessments of } \\
\text { developing HOT skills }\end{array}$ & 27 & 43 & 83 \\
\hline
\end{tabular}

E. Determining a coefficient of success in HOT skills development

Analysis of HOT skills development in students is based on comparison of formative assessments of HOT skills development and fixed assessments of skills. Such comparison is realized by using a formula:

$$
\delta\left(\mathrm{s}_{\mathrm{i}}\right)=\left(\mathrm{g}\left(\mathrm{s}_{\mathrm{i}}\right)-\mathrm{g}\right) / \mathrm{g}, \quad-1<\delta\left(\mathrm{s}_{\mathrm{i}}\right) \leq 0
$$

where

$\mathrm{g}\left(\mathrm{s}_{\mathrm{i}}\right)$ is a formative assessment of the development of the certain HOT skill (some or all skills of the defined type) in student $\mathrm{s}_{\mathrm{i}}$; $\mathrm{g}$ is a fixed assessment of all HOT skills of defined type. It is the sum of the fixed assessments of particular skills; $\delta\left(\mathrm{s}_{\mathrm{i}}\right)$ is a coefficient of success of HOT skills development in student $\mathrm{s}_{\mathrm{i}}$.

The value of the coefficient of success characterizes HOT development relative to separate skills and their combinations. Thereby, analysis of results of HOT skills development should be realized by examination of values of the coefficient of success. The proposed coefficient of success of HOT skills development serves as an effective tool of quantitative and qualitative analysis of developing thinking skills.

The fixed assessment of the skill "Selecting" is $5 \%$, and a fixed assessment of all HOT skills of "Analytical" type is g= $40 \%$ (Table1). The student $s_{1}$ developed the skill "Selecting" (Table 2). Hence, his formative assessment relative to this skill is $\mathrm{g}\left(\mathrm{s}_{1}\right)=5 \%$. Then, the value of the coefficient of success of student $\mathrm{s}_{1}$ relative to this skill according to formula (1) is $\delta^{\mathrm{s}}=-0.875$.

The student $\mathrm{s}_{3}$ has the most formative assessment of analytical skills development in a study group. The dominant part of skills developed by student $\mathrm{s}_{3}$ is constituted by the skills "Contrasting, Ordering, and Evaluating". The formative assessment is $\mathrm{g}\left(\mathrm{s}_{3}\right)=35 \%$ (Table 2). The fixed assessment of all HOT skills of the "Analytical" type is $\mathrm{g}=40 \%$ (Table1). Then, the coefficient of success of the development of analytical skills by student $\mathrm{s}_{3}$ according to formula (1) is $\delta^{\mathrm{A}}\left(\mathrm{s}_{3}\right)=-0.125$. It allows the conclusion that student $\mathrm{s}_{3}$ has an inessential lack of analytical skills since: $\delta\left(\mathrm{s}_{3}\right)=-$ 0.125 and the maximal value of the coefficient of success of developing skills equals zero.

The fixed assessment of developing creative thinking skills is $\mathrm{g}=60$ (Table1). The student $\mathrm{s}_{3}$ has the most assessment of developing creative skills in a study group. The assessment is $\mathrm{g}\left(\mathrm{s}_{3}\right)=48 \%$ (Table 3 ). Then, the coefficient of success of developing creative skills in student $\mathrm{s}_{3}$ according to formula $(1)$ is $\delta^{\mathrm{C}}\left(\mathrm{s}_{3}\right)=-0.2$. Comparison of the coefficient $\delta^{\mathrm{A}}\left(\mathrm{s}_{3}\right)=$ -0.125 with the coefficient $\delta^{\mathrm{C}}\left(\mathrm{s}_{3}\right)=-0.2$ allows to conclude that student $\mathrm{s}_{3}$ has had more success in development of analytical skills.

The fixed assessment of developing HOT skills in a student is $100 \%$ (Table1). Combined formative assessment of the development of the analytical skills and the creative skills in the student $s_{3}$ is $83 \%$ (Table 4 ). Then, the coefficient of success of the HOT skills development in student $\mathrm{s}_{3}$ according to formula $(1)$ is $\delta\left(\mathrm{s}_{3}\right)=-0.17$. It allows the conclusion that the student $\mathrm{s}_{3}$ has an inessential lack of development of HOT skills since the maximal value of the coefficient of success of HOT skills development equals zero.

\section{F. Developing Adaptive Assessments}

Examination results analysis of HOT skills development with the help of the determined coefficient of success reveals a lack of development certain skills in individual students as a study group. It reflects the need for assessment adaptation in the process of HOT skills development for individual students as for a study group. Adaptation of assessment is realized by change of the fixed HOT skills assessments by crossing from one phase study to another.

Changing the fixed assessments is carried out for individual students or for a study group in the following way. If examination results revealed a lack of the certain skill development for one or some students then fixed assessment of this skill is increased by an instructor. If the value coefficient of success of developing the defined type of skill is low, then fixed assessment of this skill type is increased by an instructor. Fixed assessment of a skill type having a larger value coefficient of success of developing skills is decreased. It induces the students to develop the needed skills. 


\subsection{A Computer Assessment Tool for HOT skills development}

The aim of the CAT is to promote students' HOT skills development through facilitation of an assessment process for an instructor. On the basis of the data received from an instructor the CAT forms the next outcomes:

- Formative assessments of the analytical and creative skills development of individual students for a certain phase of a course study

- Average formative assessments of the analytical and creative skills development of individual students as a result of a course study

- Combined formative assessments of developing HOT skills in individual students

- The values of the coefficient in success developing certain type skills of individual students

- The values of coefficient in success developing the HOT skills of individual students

- Average formative assessments of the analytical and creative skills development of a class relative to a certain phase of course study and a course

- Average formative assessments of the HOT skills development of a class relative to a study phase and a course

- The thinking skills that revealed poor and improved development relative to every student

- The thinking skills that revealed poor and improved development by all students

- The best student and the worst student relative to HOT skills development

- $\quad$ The list of advanced students.

An instructor and students interact with each other and with the CAT. The interaction between an instructor and students is as follows. An instructor leads PBL of the students. He also offers control questions and problems for students in order to assess analytical and creative skills development. The students interact with an instructor during PBL and present answers for the control questions and the results of problem solving. During the interactions between an instructor and the CAT, an instructor fills in the data on the form for assessment of analytical and the creative skill development (similarly by the Table 2 and the Table3). The data is:

- a list of the analytical skills and fixed assessments of the analytical skills development

- a list of control questions

- the fixed assessments for the control questions

- the results of the student answers for the control questions

- a list of the creative skills and the fixed assessments of creative skills development

- the results of developing the corresponding creative skills by the students due to the problem solving

The CAT gives to an instructor the above-mentioned outcomes. During the interactions between a student and the CAT, a student inquires of the CAT about assessments of his (her) HOT skills development. The CAT gives to a student: formative assessments of analytical and creative skills development as a result of a study phase of the course; average formative assessments of the analytical and creative skills development as a result of course study; the thinking skills that had poor and improved development.

\section{Conclusion and Future Work}

This paper has introduced a straightforward systematic approach to computer-mediated assessment of developing HOT skills needed for problem solving. The Computer Assessment Tool is used for assessing HOT skills development in students. The approach promotes effective development of HOT skills in students, motivates active learning, and facilitates use of PBL model by an instructor and students.

The approach provides complexity, adaptability, flexibility, responsiveness, and versatility of assessing HOT skills development. Complexity of assessment is expressed in forming the combined assessments of HOT skills of different types. Adaptation of assessment to HOT skills development of individual students and a study group is represented by changes in an instructor's fixed assessments of students' HOT skills by crossing from one phase of PBL to another. Change of fixed skills assessments is realized through analysis of values of the proposed coefficient of success of HOT skills development. Flexibility, responsiveness, and versatility are reached due to use of a CAT.

Further research will be directed towards enhancement of the proposed approach, analysis of its efficiency as a result of practical use, and creation of an intelligent tool for management of HOT skills development. 


\section{References}

Alam, Firoz. (2014). Using Technology Tools to Innovate Assessment, Reporting, and Teaching Practices in Engineering Education (Advances in Higher Education and Professional Development, IGI Global; 1 edition.

Amador, Jose A., Miles, Libby \& Peters, Calvin B. (2006). The Practice of Problem-Based Learning: A Guide to Implementing PBL in the College Classroom, Jossey-Bass; 1 edition.

Baden, Maggi S., Major, Claire H. (2004). Foundations of Problem Based Learning (Society for Research into Higher Education), Open University Press; 1 edition.

Barell, John F. (2006). Problem-Based Learning: An Inquiry Approach, Corwin; 2nd edition.

Barret, Terry, Moore, Sarah. (2010). New Approaches to Problem-based Learning: Revitalising Your Practice in Higher Education, Routledge; 1 edition.

Bednarz, Timothy F. (2011). Developing Critical Thinking Skills: Pinpoint Leadership Skill Development Training Series, Majorium Business Press.

Boud, D. \& Feletti, G. (1997). The Challenge of Problem-Based Learning, London: Kogan Page.

Bransford, John D., Brown, Ann L. \& Cocking, Rodney R. (1999). How People Learn: Brain, Mind, Experience and School, Washington DC, The National Academies Press.

Brookhart, Susan M. (2010). How to Assess Higher-Order Thinking Skills in Your Classroom, Association for Supervision \& Curriculum Development; 1 edition.

Cottrell, Stella. (2011). Critical Thinking Skills: Developing Effective Analysis and Argument, Palgrave Macmillan, 2nd edition.

Cottrell, Stella. (2013). The Study Skills Handbook, Palgrave Macmillan, 4th edition.

Duch Barbara, Groh Susan, Allen Deborah. (2001). The Power of Problem-Based Learning, FALMER/KP; 1 edition.

Hannafin, Michael J. \& Land, Susan M. (1997). The foundations and assumptions of technology-enhanced student-centered learning environments, Instructional Science 25: Kluwer Academic Publishers, 167-202.

Jonassen, D. (1998). Designing Constructivist Learning Environment, In Reigeluth, C.M (Ed.), Instructional theories and models, Mahwah, NJ, 2 edition.

Knight, P.T. (2000). The Value of a Programme - wide Approach to Assessment, Assessment and Evaluation in Higher Education, 25(3), 237-251. http://dx.doi.org/10.1080/713611434

Lovie-Kitchin, J. (2001). Reflecting on Assessment, In Schwartz, P. et al. (Eds), Problem-Based Learning: Case Studies, Experience and Practice. London: Kogan Page.

Ma, J. \& Zhou, D. (2000). Fuzzy set approach to the assessment of student-centered learning, IEEE Transaction on Education, Volume 43, Issue 2, 237-241. http://dx.doi.org/10.1109/13.848079

Ma, J. (2002). Group decision support system for assessment of problem-based learning, Education, IEEE Transition, 39(3), 388-393. http://dx.doi.org/10.1109/13.538763

Macdonald, Ranald \& Savin-Baden, Maggi. (2004). A Briefing on Assessment in Problem-based Learning, Learning and Teaching Support Network. Available at: ftp://www.bioscience.heacademy.ac.uk/Resources/gc/assess13.pdf

Moallem, Mahnaz. (2007). Assessment of Complex Learning Tasks: A Design Model IADIS, In Proceedings of International Conference on Cognition and Exploratory Learning in Digital Age (CELDA). Available at: http://www.coe.missouri.edu/ jonassen/courses/CLE/

Papanastasiou, Elena. (2014). Adaptive Assessment, Encyclopedia of Science Education, Springer, 1-2. http://dx.doi.org/10.1007/978-94-007-6165-0

Pettigrew, Catharine \& Scholter, Ingrid. (2010). Using Assessment to Promote Student Capabilities, In Barrett Terry \& Moore Sarah (Eds), New Approaches to Problem-based Learning: Revitalising Your Practice in Higher Education, Routledge, 1 edition.

Savery, J. R. (2006). Overview of Problem-based Learning: Definitions and Distinctions, The Interdisciplinary Journal of Problem-based Learning. Spring, 1 (1): 9-20. http://dx.doi.org/10.7771/1541-5015.1002

Schwartz, Peter, Mennin Stewart, Webl Graham(Eds). (2001). Problem Based Learning: Case Stadies, Experience and Practice, Kogan Page Limited.

Tillema, H. (2010). Formative Assessment in Teacher Education and Teacher Professional Development, International Encyclopedia of Education, third edition, Elsevier. 